\title{
$\mathrm{PH} 9 \mathbf{1}_{\text {panorama }}$
}

\section{DCurator: una herramienta para la inspección de esculturas a través de tomografía computacional}

\begin{abstract}
3DCurator se ha desarrollado para permitir el examen 3D del interior de esculturas no metálicas. Actualmente el software disponible en el mercado para el análisis de estos datos está orientado a la medicina y es, además de complejo, generalmente caro. Por este motivo se ha trabajado en la creación de una herramienta sencilla, configurada inicialmente para la visualización óptima del interior de esculturas de madera, con la que los restauradores e investigadores del arte puedan explorar sin generar cortes y tomen medidas sin que exista riesgo de dañar, en ningún momento, la figura examinada.
\end{abstract}

Francisco Javier Bolívar Lupiáñez | Departamento de Lenguajes y Sistemas Informáticos, Universidad de Granada Francisco Javier Melero Rus | Departamento de Lenguajes y Sistemas Informáticos, Universidad de Granada

URL de la contribución <www.iaph.es/revistaph/index.php/revistaph/article/view/3906>

El uso de técnicas como la tomografía computacional (TC o TAC), la tomografía por emisión de positrones (PET) o la imagen por resonancia magnética (IRM) está muy extendido en el campo de la medicina, ya que gracias a estas técnicas se pueden obtener imágenes de alta resolución del interior del paciente con las que poder detectar enfermedades. No obstante, su uso no se restringe exclusivamente a este campo y ya ha sido aplicado con anterioridad en otras áreas de conocimiento, como en la arqueología para el estudio interno de momias.

Con el software 3DCurator se pretende trasladar el uso esta técnica de obtención de imágenes al campo de la restauración y el estudio de bienes culturales muebles que hasta ahora, de forma prácticamente única, viene usando radiografías convencionales para examinar internamente una obra. Las radiografías presentan el gran problema de la pérdida de una dimensión espacial y el solapamiento de información por la superposición de planos paralelos a la proyección.

A diferencia de los datos obtenidos con una radiografía, los que se obtienen mediante una TC conservan la información tridimensional, de forma que el modelo obtenido puede ser visualizado tridimensionalmente, o seccionado con un plano arbitrario para generar una imagen 2D, lo cual permite realizar un análisis completo del interior de la figura escaneada.
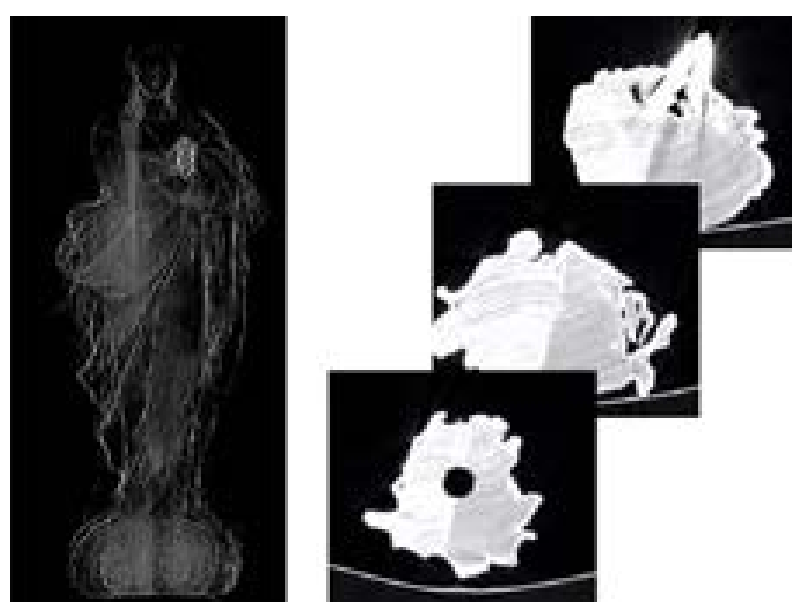

Imagen izquierda obtenida al hacer una radiografía. En la derecha varios cortes axiales generados al realizar una tomografía computacional

El uso de esta técnica puede resultar muy útil para restauradores que podrían, entre otras cosas:

$>$ Identificar y determinar con precisión la orientación y dimensiones de elementos ocultos bajo la policromía, como pueden ser clavos.

$>$ Detectar problemas estructurales en el embón.

> Distinguir las distintas piezas de madera que componen la figura y ver el estado de las juntas.

> Localizar ataques producidos o por insectos xilófagos o por otros agentes de tipo biótico, determinando las trayectorias exactas de las galerías.

> Identificar reestucados y repolicromados. 


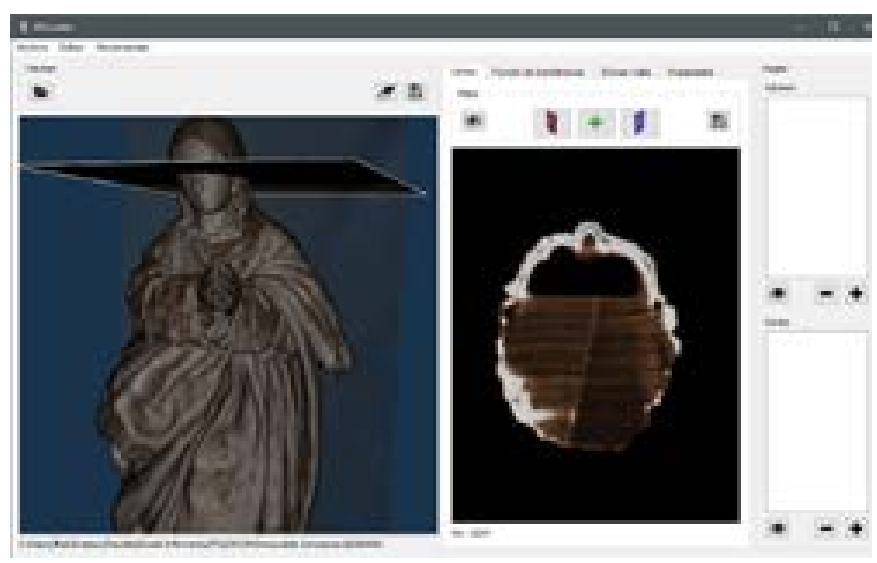

Reconstrucción volumétrica de la escultura a partir de sus cortes CT, y visualización de un corte arbitrario donde se pueden ver los distintos bloques de madera existentes

Lo mismo ocurriría con los historiadores del arte para comparar técnicas de ensamblaje, montaje de embón o estucado y así autentificar, datar o atribuir una obra. No obstante existen limitaciones como el tamaño de las figuras ya que estos aparatos están pensados para un uso anatómico y son lo suficientemente grandes como para que pueda entrar una persona. Aunque la mayor parte de las esculturas no se ven afectadas por este problema.

En la literatura científica podemos destacar la tesis doctoral de Francisca Sarrió de la Universidad Politécnica de Valencia, que realizó un estudio a distintas esculturas policromadas en madera usando las imágenes que había obtenido al someterlas a una TC. Para realizar este estudio, la autora usa un software orientado a la medicina, quedando la visualización de los modelos digitalizados poco natural. Además, como se ha indicado anteriormente, el software médico es excesivamente complejo para los requerimientos que pueda tener el examen de una escultura.

Con 3DCurator proporcionamos un software gratuito, libre, sencillo y fácil de utilizar. Cuando se leen los datos se genera automáticamente una reconstrucción en 3D de la figura para obtener una vista general de esta. Este modelo tridimensional viene acompañado de un plano que el usuario puede mover y rotar libremente para que, en el visor de la derecha, pueda ver el corte generado con éste.

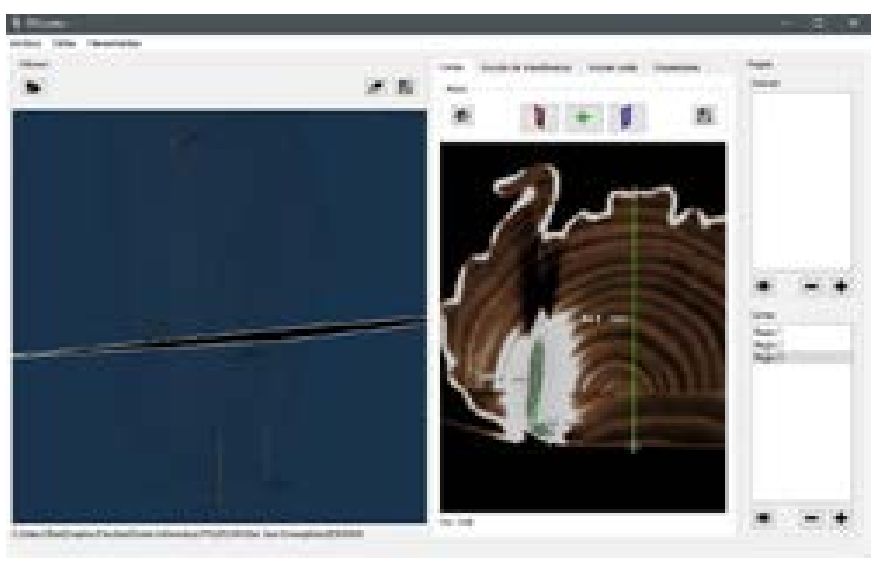

Reconstrucción en 3D mostrando solo elementos metálicos (imagen izquierda) y varias medidas realizadas (imagen derecha)

Para poder visualizar el objeto en 3D, en cualquier visor de TC es necesario definir unos parámetros de visualización, para determinar qué elementos son transparentes, con qué color se visualizan y la superposición. Es lo que se denomina una función de transferencia. En 3DCurator, para que el usuario pueda abstraerse de la complejidad de este concepto proporcionamos distintos presets con funciones de transferencia predefinidas para visualizar madera, estucado y metales, así como uno genérico, usado por defecto, con el que ver todos estos materiales conjuntamente. No obstante, también se permite editar estas funciones.

Otra funcionalidad de 3DCurator es poder definir distintas herramientas para tomar medidas reales sobre el modelo volumétrico tridimensional. Pudiéndose medir los agujeros, la anchura de los anillos de la madera, elementos metálicos e incluso el grosor de la capa de estucado.

Entendemos que el conocimiento interno de una escultura es primordial para realizar posteriormente un trabajo de conservación y restauración de calidad y que son muchos los beneficios de usar una herramienta sencilla y gratuita con la que poder obtener información muy valiosa, sin tener que dañar la escultura. Además elimina la barrera del coste del software comercial existente y la de usabilidad que plantea la complejidad del software médico existente en el mercado. 